\title{
La Politica de Empleo de la Unión Europea
}

\author{
Miguel C. Rodriguez-Piñero Royo \\ Emilia Castellano Burguillo \\ Universidad de Huelva
}

RESUMEN:

Nadie duda que la politica social jugara un papel impontante en el futum de la Linión Europea, si la idea del mercado ánico pretalece sobre la Europa de los ciudadanos. En cualquier caso. el problema del empleo ba estado presente desde los origenes de la Comunidad Económica Europea pero como un problema menor. Actualmente, ba llegado a ser in factor importante en la farmacion de la politica económica general.

Este estudio muestra un ancilisis criticu de las puliticas comunitarias de empleo. Se estuclian tres periodos diferentes: 1) los antecedentes de las politicas de empleo en la Comunidad que terminaria con el Tratado de Maastricht, el cual establece como objetivo promover un mayor nivel de empleo: 2) un segundo periodo en el cual el empleo es una prioridad en la consinuccionn de uma Europa integrada: el Tratado de la Unión; 3) nuetas acciones y procesos comunitarios para el empleo posteriores al Tratado de Amsterdam.

Palabras clave: procesos comunitarios de empleo. Tratado de Amsterdam.

ABSTRACT:

It is difficult to believe that social policies will play an important part in the future in Europe, if the idea of the Europe of the market prevails on the Europe of the citizens. Nevertheless, the employment problem was present since the beginning of the European Economic Community, although as a minor problem. At present, it has become an important factor in the definition of the general economic policy. This paper presents a critical analysis of the Employment Community Policies. Three different periods are presented:1) the old employment policy in the Community that ends with the Maastricht Treaty that establishes the objective of promoting a higher level of employment; 2) a second period in which employment is a priority in order to build an Integrated Europe: The Union Treaty; and 3) new Community actions and processes for employment following Amsterdam Treaty.

Key words: Employment Community process. Amsterdam Treaty. 


\section{Presentación}

La afirmación de que la política de empleo constituye uno de los núcleos esenciales de la actividad de las administraciones públicas y de los operadores jurídicos no puede ser discutida en la actualidad. Los distintos trabajos que se insertan en este número monográfico así lo corroboran. No es de extrañar, por ello, que también la Unión Europea, como poder público supranacional, haya desarrollado su propia política de empleo dentro del ámbito de sus poderes y competencias.

Cuando se habla de "políticas de empleo" se está haciendo referencia a una realidad muy compleja, integrada por una multitud de medidas de todo tipo. En sentido amplio, prácticamente cualquier institución del Derecho del Trabajo podría ser integrada en esta categoría, en cuanto todas tienen en cuenta a la hora de su diseño a las consecuencias que tendrán sobre el empleo. Tanto más cuando se llega a hablar del conjunto del Derecho del Trabajo como de un auténtico "Derecho del Empleo", que habría interiorizado la promoción de éste hasta el punto de alterar su naturaleza y su código genético ${ }^{1}$. Incluso si se adopta una acepción más estricta se incluiría un abanico muy extenso y variado de cuestiones: políticas activas y pasivas, medidas de seguridad social, reformas laborales, ayudas financieras, formación profesional, fondos estructurales...

Esta variedad supone una complicación cuando se está hablando de Derecho Comunitario, condicionado por la existencia de unas bases competenciales claras en cada una de sus intervenciones. La existencia de una noción clara de "política de empleo" se hace imprescindible si ésta a ha de actuar como título competencial para la adopción de medidas comunitarias; tanto más cuando en el momento actual de la política social comunitaria existe un tratamiento netamente diferenciado entre el empleo y otras cuestiones laborales, tanto en su base normativa como en su mecánica de funcionamiento e incluso su propia filosofía.

Se da la circunstancia, además, de que la propia idea de lo que son las políticas de empleo comunitarias ha ido variando con el tiempo, como consecuencia sobre todo de los cambios normativos experimentados por la Comunidad en este punto. En los primeros años de la Comunidad, por "política de empleo" se entendía, por ejemplo, la libertad de circulación de los trabajadores, algo que, directamente relacionado como ésta con el empleo y el funcionamiento de los mercados de trabajo, hoy se consideraría excluido de esta política. En los años ochenta por política de empleo de la Comunidad se estaba pensando, sobre todo, en fondos estructurales, particularmente el Fondo Social Europeo, y las acciones financiadas por éstos en materia de

1. Por todos, MOLINA NAVARRETE, "El Derecho del Trabajo propugnado por las leyes de reforma del mercado laboral: su reelaboración como Derecho de la Empresa y como Derecho del Empleo", Revista de Trabajo y Seguridad Social. Centro de Estudios Financieros, n¹52, 1995, pg.37. 
formación. En los años noventa, cuando se habla de política de empleo se está hablando sobre todo de los procesos que integran el denominado "Pacto Europeo por el Empleo". Si no se realiza un acotamiento previo del objeto material de atención se corre el peligro de que al final falte una coherencia en los temas tratados, particularmente si se adopta una visión evolutiva como la que en este trabajo se analizará.

De todas las posibles visiones de la política de empleo va a ser la última de las perspectivas señaladas la que adoptemos en este trabajo. Buscaremos definir el concepto más actual de "política comunitaria del empleo", partiendo de las bases constitucionales que de ésta se establecen en el Tratado de Roma; que es, en el fondo, la versión vigente, técnicamente adecuada de ésta ${ }^{2}$. El Título VIII del Tratado, dedicado de forma monográfica a esta política, nos servirá de base para delimitar el objeto de nuestro estudio. Otras cuestiones igualmente relevantes, como formación profesional y fondos estructurales, recibirán una atención menor, en cuanto se integren en esta política de empleo en sentido técnico.

La metodología que se seguirá será la de identificar los orígenes de esta política comunitaria, y las claves que la explican; para después definirla en su momento actual, tanto en sus aspectos procedimentales como institucionales. Ello nos obliga a seguir un tono marcadamente descriptivo en algunas de sus partes, que en otras se vuelve más crítico a medida que van surgiendo cuestiones problemáticas del análisis del Derecho vigente. El análisis seguirá el método jurídico tradicional, describiendo y explicando las instituciones jurídicas a medida que éstas vayan surgiendo; aunque en una política de este tipo es inevitable pasar continuamente a un plano valorativo y de política del Derecho. No seguiremos, por el contrario, el método interdisciplinar al que los autores están acostumbrados, dada la extensión y la finalidad de este trabajo. En consecuencia, obviaremos, por conocidos, los datos relativos a la situación del mercado de trabajo en Europa, que podrían servir para entender mejor algunos de los aspectos normativos que se aportan, pero que alargarían y complicarían en exceso este trabajo. Tampoco se suministrarán otros datos económicos igualmente relevantes, como los aspectos financieros de las distintas políticas de empleo, el reparto de fondos estructurales, etc...

El trabajo que ahora se presenta debe ser entendido en el contexto de una línea de trabajo sobre Derecho Social Comunitario que sus autores han venido desarrollando en los últimos años. En concreto, enlaza directamente con el estudio sobre "Aspectos Sociales del Tratado de Ámsterdam", publicado dentro del volumen coordinado por Aragón Medina sobre "EURO y empleo", y publicado por el Consejo Económi-

2. Recientemente CABEZA PEREIRO, "La cuestión social en el derecho originario de la Unión Europea", Documentación Laboral, n63, 2000, pg.27 sigts. 
co y Social en Madrid, en 1999, al que desarrolla y actualiza en la parte correspondiente a políticas de empleo.

\section{Desarrollo de la Política de Empleo de la Unión Europea.}

\subsection{Antecedentes de la política de empleo comunitaria.}

El origen de la intervención comunitaria en materia de empleo puede encontrarse en algunas de las primeras normas sobre política social europea. El Tratado fundacional de la hoy Unión Europea, firmado en Roma en 1957, no establecía en su artículo $2^{\circ}$, según su redacción original, la realización de un alto nivel de empleo y de protección social como objetivo principal. Ha sido la ampliación del contenido de este precepto, y por tanto, de los objetivos de la UE, la que ha llevado hasta la constitucionalización de los asuntos relacionados con el empleo ${ }^{3}$.

Es cierto que dicho Tratado originario contemplaba la libre circulación de personas, servicios y capitales, como objetivo cuya consecución se realizaría en los años siguientes; pero siempre para salvaguardar el interés económico inspirador de la Comunidad Económica Europea, y no como antesala de una política de empleo en los quince Estados miembros que actualmente constituyen la Comunidad Europea. También servía de muestra de este interés inicial, aunque escaso, en cuanto a cuestiones de Política Social, el Tratado de Roma establecía el régimen jurídico del Fondo Social Europeo, institución que hoy tiene como función precisamente la de "mejorar las posibilidades de empleo de los trabajadores en el mercado interior y contribuir asi a la elevación del nivel de vida ${ }^{\prime 4}$. Esta primitiva política de empleo comunitaria se ha desarrollado a lo largo del proceso de integración europea y hoy se mantiene activa.

A pesar de todo ello, es preciso reconocer el escaso interés que inicialmente tuvieron, para los fundadores de la $\mathrm{CEE}$, las cuestiones que podrían encuadrarse en el genérico concepto de "Política Social", el empleo incluido. El objetivo principal, al que subordinar todos los demás, era la consecución de un "Mercado Único" donde poder hacer circular, sin obstáculos de ningún tipo, las riquezas de los países miembros. Será el desarrollo de ese Mercado Único, y sus propias anomalías, las que impongan el tratamiento comunitario de cuestiones relacionadas con la llamada Política Social, y en particular, con el empleo

El desarrollo de la política social comunitaria es bien conocido, y no requiere comentario por ello. Sólo es preciso destacar aquellos acontecimientos con alguna relevancia en el tema que nos ocupa, la política de empleo. Entre éstos, la promulgación

3. El contenido del actual artículo 2 TUE ha sido incorporado tras la aprobación del Tratado de Amsterdam en 1997.

4. Según su redacción actual. art. 146 (antiguo artículo 123). 
en diciembre de 1989 de la Carta de los Derechos Sociales Fundamentales de los Trabajadores. Esta Carta fue firmada por once de los doce paises que en ese momento eran miembros de la Comunidad Económica Europea. Como se señala en su exposición de motivos, las conclusiones del Consejo Europeo de Madrid de ese año habían puesto de manifiesto que "... J en el marco de la construcción del mercado único europeo, es conveniente otorgar a los aspectos sociales la misma importancia que a los aspectos económicos y que, por consiguiente, deben ser desarrollados de forma equilibrada".

El empleo comienza a ser tratado como una materia tanto económica como social, en cualquier caso prioritaria. Se hacen consideraciones como que "la realización del mercado interior constituye el medio más eficaz para la creación de empleo y para garantizar el máximo bienestar en la Comunidad; que el desarrollo y la creación de empleo deben ser la primera prioridad en la realización del mercado interior; que corresponde a la Comunidad hacer frente a los desafios del futuro en el plano de la competitividad económica, teniendo en cuenta, en particular, los desequilibrios regionales (...l y que el consenso social contribuye a reforzar la competitividad de las empresas y de toda la economia, asi como a crear empleo, que, por esta razón, es condición esencial para garantizar un desarrollo económico sostenido."

Esta Carta es aprobada con un doble objetivo: por un lado, recoger en un único documento los derechos que hasta ese momento habían sido consagrados a nivel comunitario, en especial por labor llevada a cabo por los Estados miembros, por los interlocutores sociales y por la propia Comunidad Europea. Por otro, la Carta pretendía inspirar la aplicación de las modificaciones introducidas por el Acta Única Europea, desde la esfera social, de manera, que los objetivos recogidos en dicho documento no se quedaran en mera declaración de intenciones.

En concreto, los artículos 4 a 6 de esta Carta recogen algunos de los posibles significados del término empleo, y establecen como derecho fundamental "la libre elección y ejercicio de una profesión", con arreglo a las normas que la regulen. Asimismo, se consagra el derecho a una retribución "adecuada" que garantice un nivel de vida digno.

Sin embargo, más que el propio contenido de la carta, lo que interesa es su instrumento de aprobación, ya que esto va a constituir un elemento común en toda las normas aprobadas, hasta el Tratado de Amsterdam, en materia de empleo: se trata de las pautas aprobadas en las reuniones celebradas por los Jefes de Estado y Gobierno de los países miembros junto con la Comisión Europea, y que reciben la denominación de Consejo Europeo. Lo auténticamente característico de la política de empleo comunitaria de estos años anteriores al Tratado de Ámsterdam fue precisamente que ésta utilizó como instrumento principal las conclusiones de los sucesivos Consejos Europeos. 
La creación del Consejo Europeo obedeció a la necesidad de hallar una salida a las incertidumbres de la construcción europea ante la incapacidad de las principales instituciones de liderar el proceso. Desde la Conferencia de París de 1974 los máximos responsables de los Estados miembros y el presidente de la Comisión se reúnen una o dos veces por semestre, generalmente en el territorio del Estado miembro que ostenta la presidencia de la Comunidad ${ }^{5}$. A pesar de la entidad de las cuestiones debatidas en el seno de estas Cumbres europeas, su reconocimiento en el Derecho Comunitario Originario aún no se ha producido, lo que arroja como consecuencia que tampoco su "producción normativa" se realice según los dictados del procedimiento normativo común. Esto ha hecho que, desde su origen, se hayan planteado dudas sobre la auténtica eficacia normativa de esas conclusiones que se extraen al final de su realización, y que pretenden fundamentar las actuaciones ulteriores de las instituciones europeas en cuanto a la consecución de los objetivos de la Unión Europea.

En cuanto a las materias que pueden ser tratadas en el seno de estas reuniones de Jefes de Estado, en el Consejo Europeo de junio de 1977, celebrado en Londres, se precisaron las materias sobre las que se podía conocer en estas reuniones semestrales. En concreto, se señalaron cuatro grandes parcelas en las cuales se circunscribía la actuación del Consejo Europeo: temas institucionales y la posible ampliación de la Comunidad;. aspectos económicos, financieros y monetarios; . cuestiones sobre relaciones exteriores; y por último, y de mayor interés para este análisis, las políticas comunitarias en materias específicas, tales como medio ambiente, pesca, o empleo, de gran preocupación en las últimas fechas ${ }^{6}$. A continuación se analizará el tratamiento del empleo en esta sede, trabajando con las conclusiones de la Presidencia de los distintos Consejos Europeos que, tras la firma del Tratado de Maastricht se han celebrado, y que han sentado las bases para su constitucionalización con la aprobación del Tratado de Amsterdam en el año 1997.

\subsection{La política de empleo en el Tratado de Maastricht.}

El proceso iniciado con el Acta Única Europea, continúo con la firma el 7 de febrero de 1992, del Tratado de Maastricht ${ }^{7}$. A partir de esta fecha, la Comunidad Económica Europea abandona de su denominación el adjetivo económico que designaba su más claro objetivo desde su constitución, y a pasa a denominarse Unión

5. A.A.V.V. La Unión Europea. Ariel, Barcelona, 1998 pág. 175

6. En relación con esta última parcela, algún autor ha declarado que "en ocasiones los líderes europeos (reunidos en el Consejo Europeo) se ven obligados a actuar como Consejo de Ministros cuando éste se muestra incapaz de cerrar un acuerdo". Esto supone atribuir eficacia normativa a los frutos nacidos de esas cumbres europeas. A.A V.V. La Unión Europea. Ibidem. Pág. 188

7. DOCE C $n^{\circ} 191$, de 29 de julio de 1992. Sobre este texto es fundamental el trabajo de PEREZ DE LOS COBOS El Derecho Social Comunitario en el Tratado de la Unión Europea. Civitas, Madrid, 1994. 
Europea. Pero los cambios no fueron sólo de denominación, sino que otros cambios de mayor entidad tienen su origen en este Tratado.

La principal novedad, de las que aquí interesan, se encuentra en el tratamiento que, con mayor profundidad, se realiza de las cuestiones relativas a la Política Social. Si bien no fue posible su incorporación al texto del Tratado por la constante oposición del Reino Unido, sí que se consiguió acompañar este Tratado de un Protocolo, el número XIV, sobre Política Social, que daba entrada en el mismo de un Acuerdo de Política Social firmado por once Estados miembros y que pretendía seguir el camino iniciado por la Carta Comunitaria de los Derechos Sociales Fundamentales de 1989.

En cuanto a las normas de derecho originario, que se incorporan con el Tratado de 1992, cabe una mención especial del artículo 2 del mismo, que señala los objetivos de la nueva Comunidad Europea. En concreto, senala que "La Comunidad tendrá por misión promover, mediante el establecimiento de un mercado común y de una unión económica y monetaria y mediante la realización de las políticas o acciones comunes contempladas en los articulos 3 y $3 \mathrm{~A}$, un desarrollo armonioso y equilibrado de las actividades económicas en el conjunto de la Comunidad, un crecimiento sostenible y no inflacionista que respete el medio ambiente, un alto nivel de empleo y de protección social, la elevación del nivel y de la calidad de vida, la cobesión económica y social y la solidaridad entre los Estados miembros."

Junto con esta afirmación, lo que resulta más interesante en estos momentos, es el reconocimiento implícito de la actitud de "coordinación", por parte de las instituciones europeas, en relación con las actuaciones nacionales en materias como el empleo. Y esto se desprende del contenido del artículo 3 A que señala que "Para alcanzar los fines enunciados en el articulo 2, la acción de los Estados miembros y de la Comunidad incluirá, en las condiciones y según el ritmo previstos en el presente Tratado, la adopción de una política económica que se basará en la estrecha coordinación de las políticas económicas de los Estados miembros, en el mercado interior y en la definición de objetivos comunes, y que se llevará a cabo de conformidad con el respeto al principio de una economia de mercado abierta y de libre competencia".

Esa estrecha coordinación de las políticas económicas nacionales incluye a su vez una coordinación de las políticas nacionales de empleo, en la medida en que éstas forman parte del tejido económico de toda sociedad.

Por otra parte, el TUE, según su redacción original, prevé un Título VIII sobre Política social, educación, formación profesional y juventud. El artículo 118 TUE, contempla la "actividad de colaboración" que la Comisión europea realizará a partir de estas fechas con los Estados miembros en materias como "el empleo, Derecho del trabajo y las condiciones de trabajo, la formación y perfeccionamiento profesio- 
nales, la seguridad social, etc. l. J. A tal fin la Comisión actuará en estrecho contacto con los Estados miembros, mediante estudios, dictámenes y la organización de consultas, tanto para los problemas que se planteen a nivel nacional como para aquellos que interesen a las organizaciones internacionales."

Asimismo, el artículo 123 TUE (ampliado tras la reforma de Maastricht) prevé la existencia de un Fondo Social Europeo, "para mejorar las posibilidades de empleo de los trabajadores en el mercado interior y contribuir asi a la elevación del nivel de vida." Este Fondo Social estará "destinado a fomentar, dentro de la Comunidad, las oportunidades de empleo y la movilidad geográfica y profesional de los trabajadores, asi como a facilitar su adaptación a las transformaciones industriales y a los cambios de los sistemas de producción, especialmente mediante la formación y la reconversión profesionales".

Sin embargo, y a pesar de estas previsiones, el reconocimiento legal de la importancia que para la mayoría de los Estados miembros tienen las cuestiones de Política Social se produce por la aprobación Acuerdo sobre Política Social, anejo al Tratado de Maastricht. Este Acuerdo, recoge en su artículo primero, como objetivos de la Comunidad y de los Estados miembros, "el fomento del empleo, la mejora de las condiciones de vida y de trabajo, una protección social adecuada, el diálogo social, el desarrollo de los recursos bumanos para conseguir un nivel de empleo elevado y duradero y la lucba contra las exclusiones.[...]".

En cualquier caso, resulta contradictorio que, por una parte, y según el artículo 2.3 de este Acuerdo, se exija la unanimidad en el Consejo de Ministros de la Unión Europea, para la aprobación de cualquier norma que tenga por objeto la coordinación de las políticas nacionales, cuando dicha actuación tenga relación con materias como "las contribuciones financieras dirigidas al fomento del empleo y a la creación de empleo". Y por otra parte, se exija sólo mayoría cualificada para la intervención en materias como "la mejora del entorno de trabajo, de las condiciones de trabajo, la igualdad de oportunidades entre bombres y mujeres o la integración de personas excluidas, etc...". Cuando, en realidad, todas estas cuestiones van a ser fijadas, en las Cumbres europeas, como materias en las que incidir para la consecución de un alto nivel de empleo.

Resulta pues evidente el efecto de frenada que previsiones como la comentada tienen en un ámbito de la relevancia del empleo, que constituye uno de los grandes desafíos puestos de manifiestos en los niveles europeos. Es por ello que las actuaciones realizadas desde estas fechas han venido canalizadas por la vía de "conclusiones de los Consejos Europeos" que cada semestre se celebran en alguna ciudad comunitaria. Esto permite justificar el análisis de estos documentos que han sentando progresivamente las bases para la incorporación en el TUE, tras la Cumbre de Amsterdam, de un Capítulo específico sobre el empleo. 
2.3. El empleo en las Cumbres Europeas celebradas desde el Tratado de Maastricht basta el Tratado de Amsterdam.

Tras la aprobación y entrada en vigor del Tratado de Maastricht, la primera Cumbre europea que se ocupa de la materia de forma significativa es la Cumbre de Bruselas a finales de $1993^{8}$. En esta Cumbre se aprueba un plan de acción basado en el Libro blanco sobre Crecimiento, Competitividad y Empleo, que además exige para su realización de la existencia de "una economia sana, abierta y orientada bacia la solidaridad".

En noviembre de ese mismo año, se aprueba la "Resolución del Consejo, sobre el fortalecimiento de la competitividad de las empresas, en particular, de las pequeñas $y$ medianas empresas y del artesanado, para fomentar el empleo "1o. En este documento el Consejo pide a la Comisión y a los Estados miembros que "fortalezcan, en el marco de las asociaciones ampliadas, la eficacia, la coberencia y la presencia de las acciones a favor de las PYME, teniendo también en cuenta la dimensión estratégica del tamaño de las empresas". Se pone, pues, el énfasis en el tamaño de la empresa como sujeto susceptible de generar empleo. Con esta Resolución el Consejo prosigue la labor iniciada con la "Resolución de 22 de diciembre de 1986, sobre el Programa de acción para el incremento del empleo"11, en el cual el Consejo de Ministros Europeo reconocía el enorme potencial que las pequeñas y medianas empresas tenían para el desarrollo futuro del empleo. centrándose además. en materias como la formación profesional, el diálogo social y la cohesión económica y social.

Unos meses más tarde, en el Consejo Europeo de Corfú, celebrado durante los días 24 y 25 de junio de 1994, se ponen de manifiesto algunas ideas de interés. En primer lugar, se observa como el empleo empieza a ser una inquietud tanto para los ciudadanos de la Unión Europea, como para las propias instituciones comunitarias ${ }^{12}$. En segundo lugar, se apunta que la época de bonanza económica debe ser aprovechada para "acelerar reformas fundamentales, especialmente en el ámbito del empleo, en el que la situación todavia es muy preocupante"1.3. En tercer lugar, se recuerda la

8. Con anterioridad, otras reuniones del Consejo Europeo habian sido foro para el debate de cuestiones relacionadas con el empleo, así el Consejo Europeo de Edimburgo durante los días 11 y 12 de diciembre de 1992, y el Consejo Europeo de Copenhague de los días 21 y 22 de junio de 1993.

9. Conclusiones de la presidencia del Consejo Europeo de Corfú (24 y 25 de junio de 1994). http:// europa.eu.int/council/off/conclu/index. htm.

10. DOCE $n^{\circ} \mathrm{C} 326$ de 3 de diciembre de 1993.

11. DOCE $\mathrm{n}^{\circ} \mathrm{C} 340$ de 31 de diciembre de 1986.

12. En concreto se señala que "las elecciones europeas también ban puesto de manifiesto que los ciudadanos de la Unión juzgarán a ésta por la contribución que aporte en la lucha contra el desempleo y Europeo de Corfú. Ibidem. 
insuficiencia del crecimiento económico para la creación, por si sólo, de empleo, de manera que dicho crecimiento debe ir acompañado de "reformas estructurales tanto a escala de los Estados miembros como de la Unión"14. En cuarto lugar, se alienta a que los Estados miembros concentren sus esfuerzos en una serie de materias como la educación y la formación continua, la reducción de los llamados costes no salariales del trabajo, o el trabajo a tiempo parcial como alternativa a las dificultades de organización del trabajo. Asimismo, se constata la dificultad de los jóvenes para encontrar su primer empleo, una vez concluida la etapa formativa ${ }^{15}$, o la importancia que en estas materias puede llegar a tener el diálogo social. En definitiva, los compromisos asumidos en esta Cumbre europea continúan el camino iniciado tanto por el Libro Verde sobre Política Social Europea como por el Libro Blanco sobre Crecimiento, Competitividad y Empleo.

Respondiendo al compromiso asumido en Corfú se celebra la Cumbre Europea de Essen, durante los días 9 y 10 de diciembre de 1994. Esta reunión de los Jefes de Estado se abre con la proclamación de la nueva fase que se inicia después de la puesta en práctica, tras las elecciones de junio de 1994, de las reformas introducidas por Maastricht en el TCEE, en especial en las instituciones comunitarias.

Como muestra de la encadenación de actos que supone la construcción de una Unión económica y social, en las conclusiones de esta última Cumbre se fijan una serie de pilares básicos sobre los que actuar a corto y medio plazo, y entre ellos se presta una atención especial a la "prosecución y reforzamiento de la estrategia del Libro Blanco para consolidar el crecimiento, desarrollar la competitividad de la economia europea asi como mejorar la calidad del medio ambiente en la Unión Europea y, ante un desempleo todavia intolerablemente elevado, creación de más puestos de trabajo para las personas"16.

En concreto, y por lo que se refiere a la mejora de la situación del empleo, la actuación a seguir se circunscribe a cinco bloques temáticos:

- Formación profesional, en especial de los jóvenes, así como la adaptación a los nuevos avances tecnológicos para limitar el riesgo de pérdida del puesto de trabajo.

13. Conclusiones de la presidencia del Consejo Europeo de Corfú. Ibidem.

14. Conclusiones de la presidencia del Consejo Europeo de Corfú. Ibídem.

15. En concreto, se señala en las conclusiones de esta Cumbre celebrada en Corfú, que el Consejo Europeo "concede una gran importancia a que se garantice en la medida de lo posible que los jóvenes puedan pasar de su periodo de educación al trabajo, en ese contexto, acoge favorablemente el programa de la Comisión "Youth-Start".

16. Conclusiones de la presidencia del Consejo Europeo de Essen, http: // europa.eu.int/council/off/ conclu/index.htm. 
- Creación de empleo mediante una organización más flexible del trabajo existente, acompañado por unos ajustes salariales moderados y un fomento de los nuevos yacimientos de empleo, tales como los servicios sociales o el cuidado del medio ambiente.

- Reducción de los costes salariales accesorios, de manera que se incentive al empresario que quiere crear empleo.

- Aumento de la eficacia de la política de empleo. Para ello se propone actuar sobre las prácticas que estimulan, al potencial trabajador, ha rechazar ofertas de trabajo, pudiera decirse, adecuadas de manera que se mantenga "el estimulo personal de esforzarse constantemente por buscar un empleo dentro del mercado laboral en general. Este aspecto ba de tenerse en cuenta particularmente a la bora de elaborar medidas de apoyo a la renta" $"$.

- Reforzamiento de las medidas a favor de grupos más desfavorecidos por los niveles de desempleo. En particular, jóvenes con escasa formación, parados de larga duración que presentan necesidades formativas y personales diferentes al anterior grupo, y mujeres desempleadas.

A partir de esta Cumbre se pone en marcha la llamada "Estrategia de Essen" que, en resumen. consiste en el reflejo de las recomendaciones o directrices que se aprueban en el nivel comunitario en los diferentes planes nacionales sobre el empleo. Con ello, y como algún autor ha señalado, "se instauró, por primera vez en la bistoria de la Comunidad, un proceso de seguimiento de la evolución del empleo en los Estados miembros, ordenándose a los Consejos de Asuntos Sociales, ECOFIN, y Comisión que presentaran un informe anual sobre los avances logrados en los mercados laborales nacionales, asi como en la evolución de las politicas nacionales"18.

En junio de 1995, se celebró la reunión de Jefes de Estado y Gobierno en la ciudad de Cannes. En concreto, y por lu que se refiere al empleo, se constató que a pesar de los intentos de llevar a la práctica los postulados destacados en el Consejo Europeo de Essen, el índice de desempleo permanecería durante ese año en unos niveles que no eran aceptables. Se invitó a los Estados miembros a que profundizaran en sus reformas estructurales y se pidió al Consejo y a la Comisión europeos que estudiaran "el efecto mutuamente benéfico resultante de un fortalecimiento de la coordinación de las políticas ecunómicas y estructura-

17. Conclusiones de la presidencia del Consejo Europeo de Essen. Ibidem. Punto 1.4

18. Consejería de Empleo y Desarrollo Tecnológico. La politica de Empleo en la Unión Europea (I): la Estrategia Europea del Empleo. Junta de Andalucia. Sevilla, 2000. Pág. 20

19. Conclusiones de la presidencia del Consejo Europeo de Cannes. http:// europa.eu.int/council/off/ conclu/index:htm. 
les y que le informaran (al CQnsejo Europeo) sobre el mismo en su reunión de Madrid". ${ }^{19}$ Además como conclusiones de esta Cumbre se señalaron los siguientes aspectos:

- La estabilidad económica es condición sine qua non para el descenso de los tipos de interés, para una mayor inversión, y por tanto para un estímulo para el crecimiento, también laboral.

- Asimismo, se recoge el compromiso asumido por los interlocutores sociales, la Conferencia Europea de Sindicatos, la UNICE y la Unión Europea del Artesanado y de las Pequeñas y Medianas Industrias, para asumir sus "responsabilidades en la aplicación de las conclusiones del Consejo Europeo de Essen"20.

- De nuevo se pone sobre el tapete el estímulo necesario para que los empresarios lleguen a crear puestos de trabajo, sobre la base del refuerzo a "los incentivos individuales a la productividad, estimular la competencia y consecuentemente, de manera general, aumentar la flexibilidad de los mercados". ${ }^{21}$

- Se pone de relieve la importancia de las iniciativas locales de empleo como mecanismo mediante el cual canalizar las instrucciones procedentes de las esferas comunitarias, y el papel que están desempeñando las PYMES en la creación de empleo.

- La simplificación del acervo reglamentario para la creación y mantenimiento del empleo, es otra de las soluciones que ayudan a frenar el nivel de desempleo de las sociedades actuales.

- Se presentan como actividades susceptibles de crear empleo todas aquellas relacionadas con la llamada Sociedad de la Información.

En ese mismo año, en diciembre, se celebró el Consejo Europeo en Madrid, y en las conclusiones de dicha reunión, sus miembros muestran su satisfacción por la aplicación, por parte de los sujetos implicados, de la llamada estrategia de Essen, y en particular el procedimiento de seguimiento del empleo previsto en dicha Cumbre. De manera que se constata, por una parte, que los Estados miembros, en esas fechas, han "traducido las recomendaciones de Essen en programas plurianuales de empleo, que recogen medidas innovadoras que ya ban comenzado a dar sus frutos y que son el instrumento adecuado para plasmar las recomendaciones que el Consejo vaya adoptando en el ámbito socioeconómico". Y por otra parte, se constata que las instituciones europeas implicadas en el procedimiento de seguimiento de la estrategia de Essen (Consejos de Asuntos Sociales, ECOFIN, y Comisión), han realizado los debe-

20. Conclusiones de la presidencia del Consejo Europeo de Cannes. Ibidem. Punto 1.2

21. Conclusiones de la presidencia del Consejo Europeo de Cannes. Ibidem. Punto 1.3. 
res que asumieron en dicho Consejo Europeo. En este clima de satisfacción el Consejo Europeo insta a los Estados miembros para que continúen la labor, centrando sus esfuerzos en una serie de materias, tales como:

- Formación, en especial, para los desempleados.

- Flexibilidad en el tiempo y organización del trabajo.

- Control de los costes laborales indirectos y moderación salarial, sobre todo por los interlocutores sociales

- Eficacia de los sistemas de protección social, pero sin que ello suponga pérdida de interés en la búsqueda de empleo.

- Conversión de las políticas pasivas de protección al parado en políticas activas.

- Mejora de las formas de comunicación entre oferentes y demandantes de empleo.

- Fomento de las iniciativas locales de empleo.

Todo ello, en particular, para ciertos colectivos como los jóvenes, mujeres y parados de làrga duración ${ }^{22}$.

En el año 1996 se celebra un Consejo Europeo el día 29 de marzo, en Turín, y en el cual se comenzaron los trabajos preparativos para la modificación del Tratado de la Unión Europea "con el fin de crear una unión cada vez mas estrecha entre los pueblos de Europa”. Los desafíos propuestos para los años venideros tuvieron su origen en una serie de cuestiones, entre las que se sitúa el empleo junto con asuntos como el terrorismo, la inmigración, o la delincuencia internacional. En este marco, interesa la declaración, contenida en las conclusiones de la presidencia de esta Cumbre, que señala que "con objeto de cumplir el objetivo de un alto nivel de empleo, al tiempo que se garantiza la protección social, la CIG deberá examinar la forma en que la Unión podria aportar las bases para una cooperación y coordinación mejoradas con objeto de reforzar las políticas nacionales. Además, la CIG debe estudiar la posibilidad y la forma de aumentar y mejorar por medio del Tratado la eficacia y la coordinación de los esfuerzos que realizan tanto nuestros Gobiernos como los interlocutores sociales". ${ }^{23}$

22. Desde 1995 existen tres principales programas en materia de educación y formación profesional:

- Sócrates, que fomenta la movilidad de los estudiantes y la cooperación entre establecimientos de enseñanza de nivel universitario. Este programa a su vez se distribuye en diferentes programas, por ejemplo. Erasmus, Comenius, Eurídice, etc.

- Leonardo Da Vinci, que facilita el acceso a la formación profesional a través de la mejora de los sistemas nacionales de formación profesional y fomenta la innovación y el aprendizaje a lo largo de toda la vida.

- La Juventud con Europa III, que fomenta la movilidad de los jóvenes desfavorecidos fuera de las estructuras educativas para que puedan acceder a iniciativas locales que completen su formación como ciudadanos. http:// europa.eu.int.

23. Conclusiones de la presidencia del Consejo Europeo de Turín. Accesible en http://europa.eu.int/ council/off/conclu/index.htm 
De esta forma, se sientan las bases para la incorporación, en el Tratado de la Unión Europea, de un Capítulopropio sobre empleo. Además, en las conclusiones de este misma Cumbre se presenta por la presidencia de la Comisión Europea (Sr. Santer), una "iniciativa a favor de un Pacto Europeo de Confianza para el Empleo, destinado a establecer una estrategia común y coberente entre las Instituciones europeas, los Gobiernos y los interlocutores sociales". ${ }^{24}$

Tres meses más tarde se celebra la Cumbre europea de Florencia, durante los días 21 y 22 de junio de 1996, y respondiendo al compromiso asumido en el Consejo Europeo de Turín, sobre la importancia de debatir sobre el empleo de acuerdo con esa propuesta de Pacto Europeo de Confianza para el empleo, se propone "establecer un proceso abierto y flexible que permita a todas las partes interesadas adoptar compromisos concretos a su propio nivel de responsabilidad para crear un marco macroeconómico favorable al empleo, explotar al máximo el potencial del mercado interior, acelerar las reformas del mercado laboral y utilizar mejor las políticas de la Unión en beneficio del crecimiento y del empleo" 25 . En esos momentos el Consejo Europeo "subraya que es esencial un alto y sostenido crecimiento económico no inflacionario a medio plazo para reducir de forma significativa y duradera el nivel inaceptablemente alto de desempleo de la Comunidad y para luchar contra la amenaza de la exclusión social". ${ }^{26}$

Considera el Consejo Europeo, que el desequilibrio presupuestario existente en la mayoría de los Estados miembros, es el causante de la ausencia de crecimiento laboral, por ello invita a estos Estados a "redoblar sus esfuerzos de consolidación presupuestaria, teniendo en cuenta (...) la conveniencia de reducir los gastos en lugar de incrementar los ingresos, de proceder a una reestructuración selectiva de los gastos que fomente la inversión no material en capital bumano y en investigación y desarrollo, la innovación y las infraestructuras indispensables para la competitividad, $y$ de privilegiar las politicas activas para el empleo [...]". Además se destacan una serie de cuestiones, tales como:

- La necesidad de que los Estados miembros "agilicen la aplicación de las directivas relativas al mercado interior, en especial, en los ámbitos de las contrataciones públicas, servicios de inversión y seguros.

- La importancia de las redes transeuropeas de transportes, del desarrollo de las PYMES y la investigación científica y tecnológica para la creación de empleo y competitividad.

24. Conclusiones de la presidencia del Consejo Europeo de Turin. Ibídem.

25. Conclusiones de la presidencia del Consejo Europeo de Florencia. http:// europa.eu.int/council/ off/conclu/index.htm

26. Conclusiones de la presidencia del Consejo Europeo de Florencia. Ibídem. 
- Se invita a los Estados miembros a seleccionar "regiones o ciudades que puedan participar como candidatas en proyectos piloto de aplicación de pactos territoriales y locales para el empleo". Todo ello de acuerdo con la estrategia de creación y desarrollo del empleo local.

- Se fomenta las reformas del mercado laboral, en particular, en relación con el empleo público, y las políticas de servicios y formación.

- Se destaca el papel de los interlocutores sociales en materias como la inserción laboral de jóvenes, parados de larga duración, mujeres sin empleo, mediante la negociación de aspectos como el tiempo y la organización del trabajo.

Para continuar con esta labor, en el Consejo Europeo, celebrado en Dublín, durante los días 13 y 14 de diciembre de 1996, se toman una serie de decisiones significativas que se centran, por una parte, en la adopción de la llamada Declaración de Dublin sobre el empleo, que recoge las recomendaciones del informe conjunto (del Consejo y la Comisión) sobre la necesidad de:

- Proseguir la estrategia económica de crecimiento económico y empleo siguiendo las directrices acordadas sobre política económica.

- Aumentar los esfuerzos para modernizar los mercados de bienes y servicios y para aprovechar las nuevas fuentes de empleo.

- Centrarse en la eficacia del mercado laboral y en la inversión en recursos humanos.

- Hacer que los sistemas fiscales y de protección social favorezcan más la creación de empleo.

- Aumentar la conexión entre las políticas macroeconómicas y estructurales de los programas plurianuales de empleo de los Estados miembros."27.

Y por otra parte, en esta Cumbre se muestra la preocupación europea por el retraso en la transposición y aplicación de una serie de Directivas que influyen en la organización del trabajo.

3. La Polftica de Empleo en el Tratado de la Unión Europea a partir de Amsterdam.

\subsection{El empleo en la cumbre de Ámsterdam.}

Para el estudioso del Derecho Social Europeo no dejó de ser una sorpresa la reacción de los operadores jurídicos europeos ante la firma del Tratado de Ámsterdam.

27. Conclusiones de la presidencia del Consejo Europeo de Dublin. http:// europa.eu.int/council/off/ conclu/index.htm. 
Esta actitud fue de un marcado optimismo en lo que a los aspectos sociales se refiere, lo que contrasta con la decepción que provocó su antecesor directo, el Tratado de Maastricht ${ }^{28}$. Este optimismo se justifica posiblemente, en que en Ámsterdam se corrigieron gran parte de los errores y cuestiones pendientes que los negociadores de Maastricht dejaron. Pero también, sin duda, por el tratamiento que se le dio a las cuestiones relacionadas con el empleo.

En lo que a este estudio interesa, el Tratado de Ámsterdam supone un paso decisivo en la construcción de una política comunitaria de empleo, continuando con la tendencia, iniciada años atrás, de priorizar el empleo entre los objetivos y las intervenciones comunitarias ${ }^{29}$. Supone un hito fundamental, una línea divisoria entre todos los desarrollos anteriores, que podemos considerar desde esta perspectiva la prehistoria de la política de empleo comunitario, y el propio Tratado y su desarrollo posterior, que pueden ser considerados como la historia propiamente dicha de esta política.

Esta voluntad de impulsar el empleo estuvo ya presente en toda la negociación del Tratado. En efecto, en la cumbre de Amsterdam los jefes de Estado y de Gobierno de los Estados miembros de la Unión ya expresaron su disposición a hacer del empleo una de las prioridades de la Unión. De hecho, en las Conclusiones de la Presidencia del Consejo Europeo de Amsterdam, de 16 y 17 de junio de 1997, se incluyó como anexo un documento sobre "Empleo, Competitividad y Crecimiento",

28. Sobre los aspectos sociales del Tratado de Amsterdam, entre otros muchos: BARNARD, "The United Kingdom, the Social Chapter and the Amsterdam Treaty", Industrial Law Journal, septiembre 1997, pg.275 sigts.; BETTEN, "The Amsterdam Treaty: some general comments on the New Social Dimension", The International Journal of Comparative Labour Law and Industrial Relations, otono 1997, pg.188; de la misma, "The democratic deficit of participatory democracy in Community Social Policy", European Law Review, $\mathrm{n}^{\circ} 1$, 1998, pg.20 sigts; BLANPAIN. "The Treaty of Amsterdam (1997) and beyond: the end of the European Social Model?": Luxemburgo, 1997; GALIANA MORENO, "Aspectos sociales del Tratado de Amsterdam", Revista Española de Derecho del Trabajo, n88, 1998, pg.189 sigts; GOETSCHY \& POCHET, "The Treaty of Amsterdam: a new approach to employment and social affairs?", Transfer, n³, 1997, pg. 607 sigts; GOMEZ MUÑOZ, "Empleo, crecimiento y convergencia tras las reformas de Amsterdam y la Cumbre de Luxemburgo (Un análisis de la nueva Política Social Comunitaria en la Europa de la Moneda Única)", Relaciones Laborales, $\mathrm{n}^{\circ} 7$, 1998, pgs. 66 y sigts; ILLESCAS ORTIZ, "Una Unión al servicio del ciudadano", en OREJA AGUIRRE (coord.), "El Tratado de la Amsterdam de la Unión Europea. Análisis y comentarios", Madrid, 1988, pg.201 sigts; NOGUEIRA GUASTAVINO, "Crónica Internacional y Comunitaria. Los aspectos sociales del Tratado de Amsterdam", Revista del Ministerio de Trabajo y Asuntos Sociales, n7, 1998, pg.185 sigts.; RODRIGUEZPIN̄ERO BRAVO-FERRER, "De Maastricht a Amsterdam: Derechos sociales y empleo", Relaciones Laborales, n4, 1998; RODRIGUEZ-PIÑERO ROYO, "Aspectos sociales del Tratado de Ámsterdam”, en ARAGON MEDINA y Empleo, Euro-Consejo Económico y Social, Madrid, 1999.

29. Sobre el papel de las cuestiones sociales y de empleo en esta Cumbre, véase RODRIGUEZ-PIÑERO BRAVO-FERRER, "Los derechos sociales fundamentales y la conferencia intergubernamental", Relaciones Laborales, tomo 1997-I; y GOMIS, La política social y de empleo en el Tratado de Amsterdam, CES, Madrid, 1999, pg.93 sigts. 
en el que este Consejo "reafirma la importancia que concede al fomento del empleo y a la reducción de los niveles de desempleo existentes en Europa, que son inaceptablemente altos" 30 .

En esta misma cumbre se elaboró una "Resolución del Consejo Europeo sobre Crecimiento y Empleo", que parte de que "es imperativo dar un nuevo impulso para mantener decididamente el empleo en un primerísimo lugar entre los temas de la agenda política de la Unión", y que a partir de esta afirmación desarrolla una serie de líneas de actuación que marcarán las actividades posteriores de la Unión y de los Estados miembros en este campo ${ }^{31}$. Textos éstos del mayor interés ${ }^{32}$, les falta sin embargo, fuerza vinculante, ya que en ellas el Consejo Europeo se limita a invitar " $a$ todas las partes, en concreto los Estados miembros, el Consejo y la Comisión, a que se comprometan de forma decidida en la ejecución de estas disposiciones" 33 , así como a pedir a "los interlocutores sociales que asuman plenamente sus responsabilidades en el marco de sus respectivas esferas de actividad".3. .

El resultado de esta priorización es evidente, como veremos inmediatamente: el ascenso del empleo a la categoría de objetivo comunitario, y su propia constitucionalización, de un lado; y la introducción de un nuevo título monográfico sobre esta cuestión, de otro. En relación con esta reforma se considera que el "Consejo deberia intentar que las disposiciones pertinentes de este Titulo sean inmediatamente aplicables. Y se pone de relieve la vital importancia del vinculo existente entre la creación de empleo, la capacidad de encontrar trabajo y la cobesión social'ss; lo que pone de manifiesto una vez más la importancia que se atribuye al tema.

\subsection{El empleo como prioridad comunitaria en el nuevo Tratado de la Unión.}

Se ha dicho que una de las novedades más importantes que el Tratado de Ámsterdam supuso en materia laboral fue la "constitucionalización de la política social comunitaria", entendiendo por tal que los aspectos sociales fueron elevados desde la posición secundaria que habían ocupado hasta la fecha hasta una posición de primer orden, dentro del texto del mismo Tratado ${ }^{36}$. Esto es, que pasaron a formar parte integrante,

30. Conclusiones de la Presidencia del Consejo Europeo de Ámsterdam, pg.9.

31. Resolución del Consejo Europeo sobre Crecimiento y Empleo, de 16 de junio de 1997, SN 150/97 (ANEXO), pg.9.

32. Es en estos dos textos, según ILLECAS ORTIZ, donde un mayor número de innovaciones e ideas frescas sobre la política de empleo se encuentran, mucho más que en los textos normativos y vinculantes que posteriormente se aprobarian en esta ciudad; en op.cit., pg.221.

33. Punto 12 de las Conclusiones de la Presidencia, op.cit., pg.14.

34. Ibidem, en punto 13.

35. Conclusiones de la presidencia del Consejo Europeo de Amsterdam. Ibídem.

36. Por todos, GOMEZ MUÑOZ, "Empleo, crecimiento y convergencia tras las reformas de Ámsterdam y la cumbre de Luxemburgo", Relaciones Laborales, n7, 1998. 
ahora con un contenido preceptivo claro, de la Constitución Europea. Es cierto que algunas cuestiones sociales aparecían ya en la versión original del Tratado de Roma, y otras fueron introduciéndose con posterioridad. En Ámsterdam, sin embargo, la situación cambia radicalmente, y el estatus de la política social se ha visto alterado por completo respecto de lo previsto en el momento fundacional de la Comunidad. En la Comunidad Europea post-Ámsterdam la política social alcanza un reconocimiento como una de las políticas principales de la Comunidad; y dentro de ella el empleo alcanza un estatus singular.

En términos generales puede decirse que el empleo se constituye como una de las prioridades fundamentales de la Unión en el Tratado de Ámsterdam, apareciendo reflejada esta preocupación una y otra vez a lo largo de su articulado y del extenso paquete de anexos que lo acompaña. Por todas partes aparecen menciones al pleno empleo, a la promoción de "un alto nivel de empleo", etc..., empezando por la misma Exposición de Motivos del Tratado de la Unión. Quizás lo más destacable sea la introducción del empleo entre los "objetivos de la Unión"; en efecto, en el Tratado de la Unión Europea se incluye en el artículo 2 entre estos objetivos el siguiente:

"promover el progreso económico y social, un alto nivel de empleo y conseguir un desarrollo equilibrado y sostenible, principalmente mediante la creación de un espacio sin fronteras interiores, el fortalecimiento de la cobesión económica y social y el establecimiento de una unión económica y monetaria que implicará, en su momento, una moneda única, conforme a las disposiciones del presente Tratado";

Un segundo aspecto que nos demuestra este nuevo papel de la política de empleo es el de lo que el Tratado constitutivo de la Comunidad Europea denomina "principios" de la Comunidad, en los que expresa sus objetivos y finalidades: el artículo 2 , en el que se expresa "la misión" de la Comunidad, se señala lo siguiente:

"la Comunidad tendrá por misión promover, mediante el establecimiento de un mercado común y de una unión económica y monetaria y mediante la realización de las políticas o acciones comunes contempladas en los artículos 3 y 3.A, un desarrollo armonioso, equilibrado y sostenible de las actividades económicas en el conjunto de la Comunidad, un alto nivel de empleo $y$ de protección social, la igualdad entre el bombre y la mujer, un crecimiento sostenible y no inflacionista, un alto grado de competitividad y de convergencia de los resultados económicos, un alto nivel de protección y de mejora de la calidad del medio ambiente, la elevación del nivel y de la calidad de vida, la cohesión económica y social y la solidaridad entre los Estados miembros" 
La inclusión del empleo entre los objetivos de la Unión no se limitan a lo que podemos considerar objetivos generales de ésta, sino que se reiteran con ocasión de algunas de sus políticas concretas. Así, y con independencia de lo que luego se dirá respecto de la política de empleo propiamente dicha. es de destacar cómo también el artículo 136 del Tratado ha dado al empleo un papel de primer orden entre los objetivos que la Comunidad debe perseguir en su política social: se señalan entre éstos "la promoción del empleo", y "el desarrollo de los recursos bumanos para conseguir un nivel de empleo elevado y duradero". Para conseguir estos fines la Comunidad "apoyará y completarâ" la acción de los Estados miembros".

El resultado final de todo este proceso es que aparecen entremezclados, y por ello en igualdad de condiciones, objetivos económicos y sociales, que se corresponden con las distintas políticas tradicionales de la Comunidad. Al menos a nivel de principios, la política social ostenta una categoría equivalente a la de otras políticas comunitarias. Y dentro de esta política, entendida en sentido amplio, la temática del empleo ocupa un lugar central.

Coherentemente con esta priorización del empleo entre las políticas comunitarias, el Tratado de Amsterdam introduce un nuevo título en su articulado, dedicado de forma monográfica a la cuestión del empleo. Se trata del Título VIII. que incluye los artículos 125 a $130^{37}$. En este Título se establece una auténtica política de empleo con plena entidad y autonomía, cuyas líneas esenciales analizaremos inmediatamente. Esta política se presenta formalmente independiente de la "política social" en sentido estricto, y en pie de igualdad con ésta. Materialmente, en la regulación que de ella hace el Tratado se separa también de la política social tradicional, ya que aparece luertemente influenciada por las técnicas normativas utilizadas en la política económica y monetaria.

La apuesta por el empleo es importante. En realidad, es la auténtica innovación del Tratado de Ámsterdam, su gran apuesta en el campo social. Quizás más importante aún que la otra gran novedad del Tratado, la integración del capítulo social en su articulado ${ }^{38}$. Es por la vía de la política de empleo por donde la Comunidad va a ofrecer a sus ciudadanos la sensibilidad social que éstos le exigen; es principalmente por esta vía que se va a conseguir ese equilibrio entre lo social y lo económico que se fijan como nuevos objetivos de la Unión, superando el "déficit social" del que la Unión todavía adolece 39 . Por ello se ha dicho que el empleo es "el gran descubrimiento del Tratado de Amsterdam"; pero también que su tratamiento en éste supone el paso "de la nada al todo"40 que puede resultar arriesgado.

37. Que originariamente aparecieron como Título $\mathrm{V}$ bis, artículos $109 \mathrm{~N}$ a $109 \mathrm{~S}$, usando esta numeración como consecuencia de ser un título intercalado entre los artículos tradicionales del Tratado.

38. Entre otros, RODRIGUEZ-PIÑERO ROYO, ibidem; y TORRENTS MARGALEF, "La merecida normalización de la política social comunitaria", Documentación Laboral, n61, 2000, pg. 105 sigts.

39. GOMIS, op.cit., pg.93.

40. GOMEZ MUÑOZ, op.cit., pg.83. 


\subsection{El nuevo título de empleo.}

La introducción de un nuevo título sobre empleo, en paralelo al tradicional sobre política social, es expresivo de la posición de esta política dentro del esquema de las comunitarias $^{41}$. La independencia del Título VIII respecto del $\mathrm{XX}$, el de políica de empleo se explica por al menos dos razones. La primera es de índole política, pues expresa la trascendencia o importancia que se le da en el Tratado, en pie de igualdad a otras políticas con mayor tradición. En lo que a nosotros interesa, a partir de Ámsterdam hay que pensar en el Derecho Social Comunitario en términos tripartitos, con tres grandes bloques o núcleos temáticos: libertad de circulación de trabajadores, política de empleo y armonización de los ordenamientos laborales de los Estados miembros. Con esto se supera la tradicional articulación en dos grandes bloques que hace ya muchos años definía POCAR: Derecho Comunitario del Trabajo, y Derecho del mercado de trabajo europeo ${ }^{42}$.

La segunda razón es técnica: la política de empleo se articula de forma independiente porque es distinta a las otras, porque no es una política social, ni puede englobarse con ésta. Se trata de una política diferente, a medio camino entre lo económico y lo social, que toma instrumentos de una y de otra manteniendo su autonomía ${ }^{43}$.

El esquema del Título VIII es bastante simple: según la exposición de GOMIS, éste está formado por un primer grupo de tres artículos (125 a 127), en los que se fijan las finalidades que la Unión y sus miembros se fijan en materia de empleo. A continuación, el artículo 128 establece el procedimiento para la supervisión multilateral de estas políticas. El artículo 129 se refiere a las medidas de fomento del empleo. Y el artículo 130, finalmente, se refiere a cuestiones institucionales mediante la creación de un Comité de Empleo ${ }^{4 i}$.

El punto de partida de esta nueva política comunitaria es el artículo 125, en el que se establecen sus objetivos; según este precepto

"Los Estados miembros y la Comunidad se esforzarán, de conformidad con el presente título, por desarrollar una estrategia coordinada para el empleo, en particular para potenciar una mano de obra cualificada, formada $y$ adaptable y mercados laborales con capacidad de respuesta al cambio económico, con vistas a lograr los objetivos definidos en el articulo $B$ del Tratado de la Unión Europea y en el artículo 2 del presente Tratado".

41. Existe ya una cierta bibliografía monográfica sobre este capítulo. Entre otros, GOMIS, op.cit., pg.93 y sigts; NAVARRO NIETO, El tratamiento de la politica de empleo en la Unión Europea, Consejo Económico y Social ,Madrid, 2000, pg.12 sigts; ORTIZ LALIANA, "La Unión Europea y las políticas activas de empleo", Revista del Ministerio de Trabajo y Asuntos Sociales, n¹7, 1999, pg.23.

42. POCAR, Derecho Comunitario del Trabajo, Civitas, Madrid, 1985.

43. RODRIGUEZ-PIÑERO BRAVO-FERRER, op.cit., pg.227.

44. GOMIS, op.cit., pg.99. 
El compromiso de la Comunidad es explícito y evidente, si bien también expresamente limitado: los Estados y la Comunidad "se esforzarán", y este esfuerzo sólo llega, en principio, a "una estrategia coordinada". En el resto del articulado de este capítulo se hacen aún más evidentes estas limitaciones, de tal modo que todo él denota una preocupante falta de ambición de la Comunidad respecto de un problema cuya gravedad y consecuencias sin duda habrían exigido un posicionamiento más fuerte.

Esta falta de ambición se observa ya en la fijación del objetivo de esta política comunitaria, que es, como no podía ser de otra manera, el de conseguir "un alto nivel de empleo", según se señala, en dos ocasiones, en el artículo 125. Se abandona así la referencia al pleno empleo como objetivo a conseguir que habían defendido determinados Estados miembros durante la negociación del Tratado ${ }^{45}$. Este abandono de una expresión "clásica y consagrada" en los Estados miembros, quizás por no ser realis$\mathrm{ta}^{46}$, pone de manifiesto "una señal conformista o minimalista" de los firmantes del Tratado, que de alguna manera renuncian a buscar empleo para todos sus ciudadanos empleables ${ }^{47}$.

Más significativas son las limitaciones que se establecen a los instrumentos previstos en la política comunitaria de empleo: se trata de una "estrategia coordinada" entre los Estados y la Comunidad, en la que serán los Estados miembros los que desarrollarán sus respectivas políticas de empleo para conseguir los fines previstos. En el reparto de roles entre Estados miembros y Comunidad Europea aquéllos aparecen particularmente favorecidos, mientras que el papel de ésta es, en principio, reducido. Según el artículo 127 ésta contribuirá a la política de empleo "mediante el fomento de la cooperación entre los Estados miembros, asi como apoyando y, en caso necesario, complementando sus respectivas actuaciones"; según el 129. el Consejo "podrá adoptar medidas para alentar la cooperación entre los Estados miembros y apoyar la actuación de estos últimos en el ámbito del empleo".

Además, la competencia comunitaria aparece expresamente limitada: así, en el artículo 127 se señala que la Comunidad "respetará las competencias de los Estados miembros"; en el 129 se limitan las facultades del Consejo de alentar la cooperación entre los Estados a la adopción de "iniciativas destinadas a desarrollar los intercambios de información y buenas prácticas, facilitar análisis comparativos y asesoramiento, promover planteamientos innovadores $y$ evaluar experiencias, en particular recurriendo a proyectos piloto"; y en el mismo 129 se recuerda que "estas medidas no incluirán armonización alguna de las disposiciones legales y reglamentarias de los Estados miembros".

45. ILLESCAS ORTIZ, op.cit., pg.227.

46. RODRIGUEZ-PIÑERO BRAVO-FERRER, op.cit., pg.8.

47. ILLESCAS ORTIZ, ibidem. 
Esta última mención constituye la base de todo el entramado normativo del título sobre empleo, actuando a la vez como cláusula de garantía de la competencia nacional y como límite expreso de la comunitaria ${ }^{48}$. Con ello en Amsterdam se consagra y refuerza el denominado "modelo Essen" de política comunitaria de empleo: las políticas de empleo van a seguir siendo nacionales pero van a estar coordinadas desde la Comunidad $^{49}$. Por ello, quienes esperen hallar una política de empleo a un nivel semejante al de las demás comunitarias probablemente quedarán decepcionados ${ }^{50}$.

El compromiso asumido por los Estados tampoco parece, a primera vista, excesivo: tendrán que "contribuir al logro" de los objetivos de la política de empleo; deberán considerar el fomento del empleo "como un asunto de interés común"; y quedan obligados a "coordinar sus actuaciones en el seno del Consejo", todo ello por mandato del artículo 126.

Ahora bien, este reparto de papeles de partida entre los Estados y la Comunidad se ve en gran medida alterado por el procedimiento previsto por el artículo 128, quizás el aspecto más relevante de todo el capítulo de empleo, en el que se incrementan significativamente las obligaciones del Estado en esta materia. El punto de partida de todo este procedimiento es el reconocimiento de una nueva obligación-competencia de las instituciones comunitarias: examinar anualmente la situación del empleo en la Comunidad y adoptar conclusiones al respecto. Esta competencia aparece residenciada en el Consejo Europeo, lo que demuestra la importancia que se atribuye a este procedimiento; y es un elemento más, la fase final de un procedimiento largo y complejo que se reiterará año tras año cuyas fases se suceden de forma cíclica sin solución de continuidad, apoyándose las unas en las otras sin que resulte fácil identificar un principio y un final. Se trata, según se ha dicho, de un "círculo cerrado"s1.

En principio, pues, el resultado final de todo este proceso será la elaboración por el Consejo Europeo de unas "conclusiones" sobre la situación del empleo en la Comunidad; éstas serán, en realidad, el resultado final de todo un proceso en el que intervendrán numerosos sujetos, por lo que la actividad del Consejo Europeo de "examinar anualmente la situación del empleo" será más pasiva que otra cosa. El procedimiento del artículo 128 se inicia, sin embargo, también con las conclusiones del Consejo Europeo, se supone que las de año anterior al que corresponda a cada procedimiento en concreto. A grandes rasgos, el procedimiento funciona así:

48. De auténtica "prohibición de armonización" habla ILLESCAS ORTIZ, en op.cit., pg.228.

49. RODRIGUEZ-PIÑERO BRAVO-FERRER, op.cit., pg.8.

50. Esta es al menos la opinión de BETTEN, "The Amsterdam Treaty: some comments on the new social dimension", The International Journal of Comparative Labour Law and Industrial Relations, otoño 1997, ph.189.

51. ILLESCAS ORTIZ, op.cit., pg.230. 
1. A partir de las conclusiones del Consejo Europeo, el Consejo elaborará anualmente "orientaciones" que los Estados miembros "tendrán en cuenta" en sus respectivas políticas de empleo; en la elaboración de estas orientaciones aparecen involucradas distintas instituciones comunitarias:

- El Consejo Europeo, como se vio, elabora las conclusiones sobre las que "se basarán" las orientaciones.

- La Comisión elabora la propuesta de orientaciones.

- El Parlamento Europeo, el Comité Económico y Social, el Comité de las Regiones y el Comité de Empleo son consultados.

- El Consejo aprueba por mayoría cualificada.

2. Cada Estados miembro recibe las orientaciones del Consejo, y en el desarrollo de su política de empleo propia las tiene en cuenta.

3. Cada Estado miembro elabora un informe anual sobre su política nacional de empleo, que facilita al Consejo y a la Comisión.

4. El Consejo, basándose en estos informes, y tras recibir las opiniones del Comité de Empleo, examinará anualmente la aplicación de las políticas nacionales de empleo por cada Estado miembro, "a la vista de las orientaciones referentes al empleo".

5. El Consejo, sobre la base del resultado de este examen anual, prepara conjuntamente con la Comisión un "informe anual sobre la situación del empleo", y sobre la aplicación de sus orientaciones para el empleo, para el Consejo Europeo, mediante el cual éste podrá:

- examinar la situación del empleo, anualmente como le ordena el apartado $1^{\circ}$;

- comprobar la aplicación de las orientaciones para el empleo, elaboradas por el Consejo cada año de acuerdo con lo previsto en el apartado $2^{\circ}$;

- elaborar las "conclusiones" que servirán de base para la elaboración de nuevas orientaciones para el año siguiente, en cumplimiento de los apartados $1^{\circ}$ y $2^{\circ}$ de este artículo; con lo que empezará de nuevo todo el proceso.

6. Eventualmente el Consejo de Ministros podrá formular recomendaciones a los Estados miembros en la fase de examen de sus informes anuales, a la vista de éstos y "si lo considera pertinente". Estas recomendaciones se tomarán por mayoría cualifica$\mathrm{da}$, y sobre la base de una recomendación previa de la Comisión, al cual es igualmente destinataria de los informes anuales de los Estados.

Se trata, como se observa, de un procedimiento enormemente complejo, que se repite de forma continuada y cíclica, y en el que intervienen la mayoría de las instituciones comunitarias. Las conclusiones del Consejo Europeo son, a la vez, el principio y el final de todo el procedimiento. 
Las obligaciones que este procedimiento impone a los Estados miembros son diversas: primero, claro está, dar cumplimiento a las exigencias procedimentales previstas por el artículo 128, elaborando sus informes anuales y enviándolos a la Comisión y al Consejo; pero es posible, en segundo lugar, deducir otras obligaciones de carácter material, implícitamente establecidas por este artículo del Tratado. La más importante es la de adecuar su política de empleo a las orientaciones anuales elaboradas por el Consejo; no está muy claro hasta qué punto queda vinculado cada Estado por éstas, ya que, en principio, es competencia suya diseñar su propia política de empleo; y lo que la Comunidad le envía no son más que "orientaciones", indicando su denominación que no son estrictamente vinculantes. Pero lo que sí queda claro es que de alguna manera se le va a exigir una cierta responsabilidad política si no se adapta a éstas orientaciones, debiendo explicitar su incumplimiento, del que quedará constancia en el informe anual conjunto y en las conclusiones del Consejo Europeo; y debiendo además someterse a la eventual recomendación que le dirija el Consejo, que de nuevo no será vinculante pero que indudablemente tendrá un peso político considerable.

El resultado final de la operación de todo el capítulo de empleo supone un curioso equilibrio de competencias estatales y comunitarias, en el que los Estados mantienen el núcleo de sus competencias en esta materia, pero sometidos a la presión de instrumentos de presión política por las autoridades comunitarias y los demás Estados. Y en el que se declara la responsabilidad de unos y otros en la lucha contra el desempleo, que aparece como una de las prioridades tanto de la Unión como de sus miembros.

Para apoyar tanto el funcionamiento de este procedimiento como la puesta en práctica de las distintas iniciativas posibles el artículo 130 prevé la creación, por el Consejo y previa consulta al Parlamento Europeo, de un Comité de empleo, órgano de carácter consultivo para fomentar esta coordinación entre los Estados miembros en materia de políticas de empleo que supervisará la situación del empleo y de las políticas de empleo de los Estados miembros y de la Comunidad.

Desde una perspectiva de Derecho del Trabajo los instrumentos que se prevén expresamente son sospechosamente flexibilizadores: "potenciar una mano de obra cualificada, formada y adaptable" y "potenciar mercados laborales con capacidad de respuesta al cambio económico". Es llamativo que sean éstos los únicos medios que aparecen expresamente señalados por el artículo 125 como adecuados para conseguir estos fines en materia de empleo, por más que no lo sean de forma exclusiva. Parece un guiño a las posiciones más favorables a la flexibilización y a la desregulación de los mercados de trabajo, que quizás se explique como un precio a pagar por la inclusión de un capítulo sobre empleo en el Tratado.

De la misma manera cabe analizar las distintas referencias que se hacen en todo el capítulo a la subordinación de la política de empleo a la económica: de acuerdo con el artículo 126, apartado $1^{\circ}$, las políticas de empleo de cada Estado deberán desarrollarse "de forma compatible con las orientaciones generales de las políticas económi- 
cas de los Estados miembros y de la Comunidad"; y de acuerdo con el artículo 128, apartado $2^{\circ}$, las orientaciones anuales para el empleo que elabore el Consejo deberán "ser compatibles con las orientaciones generales adoptadas con arreglo a lo dispuesto en el apartado 2 del articulo 103".

También sorprende el escaso papel que se reconoce en todo este capitulo a los interlocutores sociales 52 , que sólo aparecen expresamente mencionados, y de pasada, en el artículo 126, cuando se afirma que los Estados miembros se plantearán el fomento del empleo "teniendo en cuenta las prácticas nacionales relativas a las responsabilidades de los interlocutores sociales": ni siquiera se prevé su presencia en el Comité de Empleo creado por el artículo 130, ya que este estará formado por dos miembros designados por cada Estado y por la Comisión. Ahora bien, ello no excluye en modo alguno que puedan participar en la puesta en práctica de este capítulo: a nivel nacional, de acuerdo con los procedimientos de consulta previstos en cada Estado miembros (a esto parece referirse el artículo 126); y a nivel comunitario, a través de la intervención del Comité Económico y Social en el procedimiento previsto en el artículo 128 .

\section{Los Procesos Comunitarios y el Pacto Europeo por el Emplfo.}

\subsection{La política de empleo comunitaria tras la Cumbre de Ámsterdam.}

El Título VIII del Tratado de la Comunidad Europea no dejó en modo alguno solucionada la cuestión del tratamiento del empleo en las políticas comunitarias, sino que requería un tratamiento más detallado y puntual. Éste se logró en el siguiente hito en el desarrollo de la política de empleo comunitaria, la Cumbre de Luxemburgo, celebrada en esta ciudad los días 20 y 21 de noviembre de 1997. Esta reunión fue la primera cumbre comunitaria dedicada de forma monográfica a tratar el tema del empleo. De hecho, se le denominó técnicamente como "Consejo Europeo Extraordinario sobre el Empleo". En sus conclusiones se desarrolla lo establecido por el Tratado de Amsterdam en la materia, siendo un texto fundamental para comprender la política de empleo comunitaria.

Estas conclusiones de la Cumbre de Luxemburgo cumplen una doble función. De un lado, contienen el desarrollo y la concreción de lo previsto en el título sobre el empleo introducido por el Tratado de Ámsterdam. Título al que, además, se le otorga una eficacia jurídica inmediata ${ }^{53}$. De otro lado, recoge las

52. En extenso BETTEN, "The democratic deficit of participatory democracy in Community Social Policy", European Law Review, vol.23, nº1, 1998, pg.20 sigts.

53. En efecto, en virtud de lo previsto en el apartado $3^{*}$ de las conclusiones, "el Consejo Europeo decidió que las disposiciones pertinentes del nuevo título sobre el empleo del Tratado de Ámsterdam tengan efectos inmediatos", lo que permitirá "de becho la aplicación anticipada de las disposiciones relativas a la coordinación de las políticas del empleo de los Estados miembros a partir de 1998". 
orientaciones sobre el empleo para el año 1998, haciendo posible esta aplicación inmediata del Título VIII. Esta doble naturaleza tiene como efecto, entre otros, que una parte de estas conclusiones tendrá una vigencia limitada en el tiempo, toda la parte II dedicada a las "directrices para 1998"; mientras que la otra tendrá una duración mayor, en unos casos indefinida en el tiempo, como un desarrollo directo de lo previsto en el Tratado de la Comunidad Europea, en otros plurianual.

Lo aprobado en la cumbre de Luxemburgo, y su puesta en práctica, tuvo ocasión de ser desarrollado, en cuanto al control de la aplicación del denominado "Proceso de Luxemburgo", en el Consejo Europeo celebrado en Cardiff, durante los días 15 y 16 de junio de 1998. En éste se diseñó el siguiente balance sobre la actuación de los Estados miembros, según los planes nacionales de empleo:

- Esfuerzo por fomentar la capacidad de inserción profesional de la población activa en general, y en particular, de la juventud, de los parados de larga duración y de las mujeres.

- Fomento de la educación permanente.

- Mejora de las condiciones de las PYMES y del empleo autónomo.

A la luz de estas conclusiones se propuso continuar la labor de actuación directa en materia de empleo, fijando como objetivos a perseguir:

- La cualificación y adaptación de la mano de obra a través de la formación permanente.

- El fomento de la igualdad de oportunidades entre hombres y mujeres.

- La lucha contra otras formas de discriminación, en especial, las que sufren los discapacitados, las minorías étnicas y otros grupos con desventajas en el mercado de trabajo.

- La compatibilidad de la flexibilidad y la seguridad en el trabajo.

- La revisión de la carga tributaria y prestacional de los empresarios.

- El estímulo para la creación de pequeñas empresas.

Encuentros posteriores de los Jefes de Estado y de Gobierno contribuyeron a perfilar aún más esta política, que en la práctica ha sido más el resultado de un proceso de decantación y afinado continuados que la puesta en práctica de una decisión puntual. Así, el Consejo Europeo de Viena, de 11 y 12 de diciembre de 1998, tuvo también su importancia en la concreción y desarrollo de la política de empleo comunitaria post-Ámsterdam. Y ello aunque no se trató de una cumbre monográfica sobre esta cuestión, como lo fue la de Luxemburgo: sus conclusiones, en efecto, se ocuparon de "Empleo, crecimiento, estabilidad y reforma económica". En estas conclusiones se afirmó que "el empleo constituye la máxima prioridad de la Unión Euro- 
pea $^{254}$, lo que es significativo, teniendo en cuenta el enfoque plural e integrado de los temas de los que se ocupó; $y$, sobre todo, se habló por primera vez de la necesidad de un "Pacto Europeo de Empleo", estrategia ésta que ha estructurado el conjunto de la política de empleo comunitaria hasta la fecha. Una vez más. se puso de manifiesto el nexo entre las políticas económicas y las sociales, considerando que la unión monetaria "reforzará la capacidad europea para fomentar el crecimiento, el empleo y la estabilidad" .55

El Consejo Europeo de Colonia de 3 y 4 de junio volvió a ocuparse directamente de aspectos relacionados con el empleo. En esta reunión se emitió una "Resolución del Consejo Europeo de Colonia sobre el Pacto Europeo para el Empleo. Intensificación de la cooperación para promover el empleo y la reforma económica en Europa". En este documento se continúa avanzando en el diseño global de la política de empleo para la Unión, incidiendo en la necesidad de coordinar ésta con las otras políticas impulsadas por ésta, y en la conveniencia de poner en contacto los distintos "procesos", señalando la profunda interrelación entre éstos. Se reiteró que "un elevado nivel de empleo" constituye "la prioridad absoluta" de las políticas comunitarias, como "la clave para el bienestar económico, la justicia social y la cobesión"s6. Sobre todo, se insiste en la necesidad de abrir un "diálogo macroeconómico para el fomento del crecimiento y el empleo", añadiendo así un nuevo elemento al Pacto Europeo para el Empleo, lo que ha sido denominado posteriormente como "Proceso de Colonia".

El siguiente episodio en esta construcción tuvo lugar en el Consejo Europeo de Helsinki, que tuvo lugar los días 10 y 11 de noviembre de 1999. Las Conclusiones de este Consejo Europeo se dedicaron a "Una economia competitiva, generadora de empleo y sostenible". En éstas se insiste en la necesidad de una coordinación de políticas para lograr el crecimiento económico y la creación de empleo. Estas conclusiones se ordenan en torno a cuatro grandes bloques de temas: un paquete fiscal; empleo; mercado interior, competitividad, innovación y sociedad de la información; y medio ambiente y desarrollo sostenible.

Finalmente, durante los días 23 y 24 de marzo de 2000 se reunieron los Jefes de Estado y de Gobierno en la Cumbre Europea de Lisboa, en la cual se pretendió propagar un clima esperanzador en cuanto a la creación de una auténtica unión a nivel comunitario y un adecuado nivel de empleo. Sin embargo, algunos aspectos negativos fueron puestos de manifiesto en cuanto inconvenientes para la consecución de dicho objetivo. Así por una parte, se exponen conclusiones en las cuales se muestra la confianza en que "la próxima ampliación cree nuevas oportunidades de crecimiento y empleo". Se considera que "La Unión dispone de una mano de obra en general bien

54. Punto $\mathrm{n}^{\circ} 20$ de las Conclusiones de la Presidencia del Consejo Europeo de Viena.

55. Conclusiones de la presidencia del Consejo Europeo de Viena. http:// europa.eu.int/council/off/ conclu/index.htm

56. Punto 1 de la Resolución del Consejo Europeo de Colonia sobre el·Pacto Europeo para el Empleo. 
preparada y de unos regimenes de protección social capaces de proporcionar, con independencia de su valor intrinseco, el marco de estabilidad que requiere la organización de los cambios estructurales que implica orientarse hacia una sociedad basada en el conocimiento. Se han reanudado el crecimiento y la creación de empleo".57

Pero otra parte, se constatan datos, como los que arrojan que en la Comunidad "más de quince millones de europeos carecen todavia de empleo. El indice de empleo es demasiado bajo y se caracteriza por una participación insuficiente de mujeres y trabajadores de edad más avanzada en el mercado laboral. En algunas partes de la Unión siguen siendo endémicos el desempleo estructural de larga duración y fuertes desequilibrios regionales de desempleo. El sector de servicios está subdesarrollado, en particular en los ámbitos de las telecomunicaciones e Internet. Hay una necesidad cada vez mayor de cubrir la demanda de cualificaciones, sobre todo en tecnologia de la información, sector en el que bay un número cada vez mayor de puestos de trabajo desocupados"s8

Sobre la base de estas conclusiones se celebraron los Consejos Europeos de Santa María de Feira, y de Niza, durante los meses de junio y diciembre, respectivamente, del año 2000 , y en cuyas conclusiones se manifiesta el seguimiento, en cuanto profundización, de las cuestiones destacadas en Lisboa como aspectos que inciden en la consecución del objetivo principal de la Comunidad, y en particular, en el empleo.

\subsection{El Pacto Europeo por el Empleo.}

Como se vio, el Pacto Europeo por el Empleo fue formulado como tal en las Conclusiones de los Consejos Europeos de Viena y de Colonia ${ }^{59}$. El primer comentario que merece este "pacto" es lo engañoso que resulta su denominación, al menos desde la perspectiva del comentarista español. No hay, en realidad, pacto alguno en todo esto, entendido en su acepción tradicional de acuerdo celebrado entre distintos sujetos para fijar determinada cuestión. Teniendo en cuenta que nos movemos en el ámbito de las relaciones laborales, parecía lógico pensar en un pacto entendido en este sentido de acuerdo, como una manifestación de la concertación social a nivel europeo con participación de los interlocutores sociales europeos. Algo parecido a los distintos "pactos por el empleo" que la experiencia española ha conocido en diversas Comunidades Autónomas. Como veremos, el pacto que nos ocupa es otra cosa.

Pero es que ni siquiera es un pacto en el otro sentido que de vez en cuando le dan las instituciones comunitarias, cuando hablan, por ejemplo, de "Pacto de Estabilidad", o de "Pacto por la Confianza". Ni es un acuerdo político suscrito entre los Estados miem-

57. Conclusiones de la presidencia del Consejo Europeo de Lisboa. http:// europa.eu.inv/council/off/ conclu/index.htm.

58. Conclusiones de la presidencia del Consejo Europeo de Lisboa. Ibídem.

59. Un estudio conjunto de las conclusiones de estas cumbres en NAVARRO NIETO, op.cit., pg.16. 
bros y las instituciones comunitarias, ni es tampoco una declaración de las éstas para fijar una posición política sobre un tema determinado. Tampoco es esto.

En realidad, el Pacto Europeo por el Empleo es una extraña combinación de tres "procesos" comunitarios -en la terminología comunitaria de los años noventa del siglo pasado-, dos de ellos preexistentes al diseño de esta misma noción. Se trata de los procesos de Luxemburgo, Cardiff y Colonia, cada uno de los cuales llamado así por la ciudad en que se celebró la cumbre en la que fueron diseñados. Cada uno de estos procesos tiene un objetivo particular, diferente al de los otros. Y, también, su propio método de funcionamiento y secuenciación.

En conjunto, pues, el Pacto Europeo por el Empleo no es más que la suma de tres procesos que suponen una coordinación de políticas de empleo, una política de reformas económicas, y un diálogo macroeconómico para asegurar la estabilidad. En rigor, sólo uno de los tres elementos que lo forman tiene una relación directa con el empleo, el proceso de Luxemburgo. Es la idea, esencial en el diseño comunitario, según la cual las políticas económicas y sociales han de estar intimamente unidas; y el convencimiento de que un clima de estabilidad es indispensable para lograr el crecimiento económico y del empleo los elementos que le confieren una cierta unidad. El propio "Informe al Consejo Europeo sobre el Pacto Europeo para el Empleo" expresa esta idea, al llevar como subtitulo "Una cooperación reforzada para mejorar la situación del empleo e intensificar las reformas económicas en Europa" "

El punto de partida del Pacto, tal y como éste quedo definido en el Consejo Europeo de Colonia, es que "la política de fomento del empleo debe enmarcarse en un planteamiento global que abarque políticas macroeconómicas de crecimiento $y$ estabilidad en las que se desarrollen y apliquen las Directrices para el Empleo y las reformas estructurales esenciales para fomentar la eficacia y la competitividad". El objetivo a conseguir con el Pacto es el de "contribuir a que se alcance un alto nivel de empleo en toda Europa, manteniendo al mismo tiempo la estabilidad de los precios".

Los objetivos del Pacto Europeo por el Empleo son:

- fomentar al máximo la interacción entre la evolución salarial, la política financiera y la política monetaria, de modo que éstas se apoyen mutuamente;

- seguir desarrollando y aplicar aún mejor la estrategia coordinada de empleo en el marco del proceso de Luxemburgo;

- fortalecer las reformas estructurales con el fin de aumentar la competitividad y mejorar el funcionamiento de los mercados de bienes, servicios y capitales;

Todos estos aspectos se presentan como esenciales e imprescindibles para lograr "una estrategia de empleo coherente, viable y fructífera".

60. "Informe al Consejo Europeo sobre el Pacto Europeo para el Empleo". incluido como anexo.en las Conclusiones del Consejo Europeo de Colonia. 
Un aspecto fundamental, que se repite una y otra vez en el Informe, es la participación de los interlocutores sociales. Para lograr ello, además de su presencia en el desarrollo del proceso de Luxemburgo, se diseña un proceso de diálogo macroeconómico, el proceso de Colonia, en el que se asegura expresamente su participación.

A continuación analizaremos cada uno de estos procesos por separado.

\subsection{El proceso de Luxemburgo.}

Este es el proceso más directamente relacionado con el empleo, y de hecho se le suele considerar como el único integrante de la política de empleo comunitaria, lo que no es exacto. Este proceso fue establecido en la Cumbre de Luxemburgo de 1997, y desde esta fecha ha funcionado sin interrupción, siendo objeto de evaluaciones posteriores en las cumbres que han tenido lugar con posterioridad a esta fecha. De todos los que constituye el Pacto Europeo para el Empleo, es quizás el más aquilatado y consolidado; de ahí que se le preste una especial atención en estas páginas.

En realidad, el proceso de Luxemburgo no lo es tal; si algo es, es el proceso de Ámsterdam, pues se trata del mecanismo establecido por el artículo 128 del Tratado de la Comunidad Europea. A pesar de que se optara por darle esta denominación, en la Cumbre de Luxemburgo tan sólo se produjo un desarrollo del título sobre el empleo, viniendo sus conclusiones a clarificar el funcionamiento de todo el sistema. Clarificación y desarrollo que eran absolutamente necesarios, en los términos en que la cuestión había quedado en la reforma del Tratado.

Para empezar, las Conclusiones de la Cumbre de Luxemburgo modifican la terminología del Título VIII. Se introduce, así, una nueva terminología, que no aparecía en Ámsterdam, hablándose de "directrices para el empleo" para denominar lo que el Tratado de la Comunidad Europea llama "orientaciones comunes". Sobre estas directrices para el empleo, elaboradas anualmente por el Consejo, se basará toda la política comunitaria en esta materia.

Las directrices serán definidas para toda la Unión, basadas en un "análisis común de la situación y de los ejes generales de la política que deberá llevarse a cabo para reducir el desempleo de manera duradera". En concreto, deberán fijar unos objetivos concretos, cuya realización será supervisada periódicamente conforme a un procedimiento común de evaluación de resultados”. Las conclusiones son sumamente prudentes respecto de la aplicación de las directrices, pues afirma que ésta podrá variar "según su naturaleza, sus efectos para los Estados miembros y sus destinatarios". Señala, en todo caso, tres requisitos que las directrices deberán cumplir en todo caso:

- deberán respetar el principio de subsidiariedad;

- deberán respetar las competencias de los Estados miembros, incluidas las de sus entidades regionales;

- deberán ser compatibles con las orientaciones generales de política económica; 
El papel de los Estados Miembros se centra sobre todo en la elaboración de lo que se denomina "plan de acción nacional para el empleo". A grandes rasgos, estos planes se definen como la concreción para cada Estado miembro de las directrices para el empleo, en forma de objetivos nacionales, objetivos que serán cuantificados "siempre que sea posible y oportuno", y a los que acompañará un elenco de medidas nacionales para su puesta en práctica. La suma de estos objetivos y de los instrumentos para conseguirlos en cada Estado miembro, de acuerdo con las directrices para el empleo comunes, constituye su "plan de acción nacional para el empleo", a cuya elaboración viene obligado por mandato del Tratado CE.

La utilización de esta técnica se justifica en las Conclusiones porque mediante los planes nacionales se podrán adaptar las directrices para el empleo a las características y a la situación concreta de cada Estado, así como a los medios administrativos y financieros de que dispongan. Los Estados podrán seleccionar no sólo los objetivos a conseguir, sino también las soluciones por las que se opta, e incluso los plazos previstos para lograr los resultados pretendidos, de forma coherente con el reconocimiento que en el Tratado de Ámsterdam se hacía de su competencia exclusiva en materia de diseño de las políticas de empleo.

Si bien se indica que estos planes serán elaborados "con una perspectiva plurianual", cada Estado miembro deberá elaborar el suyo cada año. El plan deberá ser remitido cada año a la Comisión y al Consejo, acompanaado de un informe sobre las condiciones para su desarrollo. El objetivo de esta obligación es múltiple:

- permitir que el Consejo examine "la manera en que los Estados miembros bayan trasladado las directrices a su politica nacional", lo que parece indicar un cierto grado de vinculación jurídica de aquéllos por éstas;

- suministrar al Consejo la información necesaria para que éste elabore su informe anual al Consejo Europeo;

- hacer posible un "principio de vigilancia multilateral" del cumplimiento por parte de cada Estado de sus obligaciones en la materia, inspirado en el que se utilizó durante el proceso de convergencia económica.

En Ámsterdam no quedó clara la eficacia jurídica de las que ahora se denominan "directrices para el empleo". Tampoco en Luxemburgo ha quedado la cuestión bien resuelta: es evidente que se mantiene la plena competencia de los Estados en el diseño de sus políticas de empleo, instrumentada jurídicamente en lo amplio de su poder de decisión al establecer sus planes de acción respectivos; pero también se prevé que el Consejo "examinará anualmente la manera en que los Estados miembros bayan trasladado las directrices a su politica nacional". Y, sobre todo, se afirma expresamente que "es crucial para la coberencia y eficacia del proceso, que todos los Estados miembros utilicen las directrices en el análisis de su propia situación, asi como en la definición de su política, y que definan su actitud con respecto a cada una 
de ellas en su plan de acción nacional para el empleo". Queda claro que los Estados deben acomodar sus medidas de empleo nacionales a la ordenación prevista por las directrices emanadas de las instituciones comunitarias, si quiera en lo que a su ordenación y sistemática se refiere; en cuanto al contenido, la clara atribución de la competencia sobre su determinación al Estado parece dejarles a éstos toda la libertad.

El Consejo Europeo reconoce expresamente la inspiración de todo este proceso en el seguido para poner en práctica la convergencia económica: las directrices para el empleo "se inspiran directamente en la experiencia adquirida en el control multilateral de las políticas económicas" (apartado 3); la estrategia coordinada para el empleo "se inspira mutatis mutandi, en el método seguido para la convergencia económica, salvando las diferencias que existen entre los dos ámbitos" (apartado 13); y se sigue un procedimiento de implementación de las directrices "análogo con el principio de la vigilancia multilateral aplicado en el proceso de convergencia económica" (apartado 16). Ello no obstante, y de una forma bastante paradójica, denomina a todo este proceso como "un método innovador"61. Lo que queda claro en todo caso es que en política de empleo se intenta lograr lo mismo que ya se había conseguido en política económica general: en las palabras del Consejo, "la misma voluntad de convergencia hacia objetivos comunes, verificables y actualizados periódicamente" (apartado 3).

Otra novedad de las Conclusiones de la Cumbre de Luxemburgo respecto a lo previsto en el Tratado de Ámsterdam se refiere al papel de los interlocutores sociales, prácticamente excluidos de la versión original del título VIII introducida entonces. Así, el Consejo inicia sus conclusiones haciendo "un llamamiento a la movilización de todos los agentes. Estados miembros, regiones, interlocutores sociales, instituciones comunitarias, a fin de aprovechar la oportunidad unica que se ofrece boy dia de cambiar el curso de las cosas asociándose a la nueva andadura coberente y resuelta definida por el Consejo Europeo" (apartado 7). Más en concreto, en el apartado 18 se afirma que "en el marco del necesario fortalecimiento del diálogo social los interlocutores sociales, a cualquier nivel, participarán en todas las etapas de este proceso, y aportarán su contribución al desarrollo de las directrices".

Pues bien, para responder a los objetivos marcados por el Proceso de Luxemburgo, tras la revisión llevada acabo por la Comisión, teniendo en cuenta las Conclusiones extraídas del Consejo Europeo de Lisboa y todas las actuaciones anteriores, en el sentido de proponer los aspectos sobre los que debían incidir las políticas de empleo nacionales, se aprueban desde el año 1998 las Directrices comunitarias para la elaboración de esos planes nacionales. Las más recientes han sido las aprobadas por el Consejo de Ministros de la Comunidad en la Decisión 2001/63/CE, de 19 de enero de 2001, relativa a las directrices para las políticas de

61. Se trata, por otra parte, de un procedimiento bastante similar al utilizado por el Consejo de Europa para verificar el cumplimiento de la Carta Social Europea, según recuerda BETTEN, que indica también la escasa eficacia que en la práctica ha tenido este procedimiento; en op.cit., pg.189. 
empleo de los Estados miembros para el año 2001. En este documento el Consejo continua con la línea, iniciada en directrices anteriores, de centrarse en cuatro aspectos a los cuales los Estados miembros deberán prestar una especial atención al elaborar los planes nacionales de empleo. Estos cuatro aspectos se han consolidado como los auténticos pilares básicos de toda la política de empleo comunitaria, y que son:

- La mejora de la capacidad de inserción profesional, en especial, de los jóvenes y de los desempleados de larga duración, basándose para ello en la detección precoz de las necesidades individuales. Además, en caso de ser necesario, habrán de revisarse y adaptarse los sistemas de prestaciones sociales, de imposición y de formación, sobre todo, en lo que respecta al aprendizaje electrónico.

- El desarrollo del espíritu de empresa y creación de empleo, mediante la simplificación administrativa y reglamentaria necesaria para que la constitución de una empresa, o el ejercicio de un trabajo autónomo no sea una carrera de obstáculos. Asimismo, se destacan el sector servicio y todo lo relacionado con la sociedad de la información como sectores emergentes.

- El fomento de la capacidad de adaptación de las empresas y de sus trabajadores, incidiendo en la organización del trabajo de forma flexible, aunque sin olvidar la seguridad y calidad en el empleo.

- El refuerzo de las políticas de igualdad de oportunidades entre hombres y mujeres, con el objetivo de elevar la tasa de empleo femenino. Para ello se fomentan las formas flexibles de organización del trabajo, la igualdad salarial, y la creación de un sistema de protección y asistencia social adecuados.

En relación con el primero de estos pilares, y partiendo de la base de que el objetivo es "crear las condiciones idóneas para el pleno empleo en una sociedad basada en el conocimiento" 62 se considera que la actuación de los Estados miembros debe dirigirse principalmente a "combatir el desempleo juvenil y prevenir el desempleo de larga duración' ${ }^{\prime 6.3}$. Para ello los Estados miembros deberán atender, principalmente, a las siguientes cuestiones:

- Proporcionar "a cada desempleado una nueva oportunidad antes de que alcance seis meses de paro en el caso de los jóvenes, y doce meses en el caso de los

62. Decisión 2001/63/CE del Consejo. De 19 de enero de 2001, relativa a las directrices para las políticas de empleo de los Estados miembros para el año 2001.

63. Decisión 2001/63/CE del Consejo. Ibídem.. Punto I. 
adultos, en forma de formación, reconversión, experiencia profesional, empleo o cualquier otra medida destinada a favorecer su inserción profesional, incluyendo, de manera más general, orientación y asesoramiento profesional individual, a fin de garantizar su integración eficaz en el mercado de trabajo"64.

- Deberán desarrollar, en colaboración con los interlocutores sociales, "politicas destinadas a prolongar la vida activa, a fin de mejorar la capacidad de los trabajadores de más edad y aumentar los incentivos para que sigan perteneciendo a la población activa durante el mayor tiempo posiblel...J."

- Asumir el compromiso de mejorar "la calidad de sus sistemas de educación y formaciónl... en particular, mediante el establecimiento de orientaciones adecuadas tanto en materia de formación inicial como de formación permanente, [...] la modernización [...] y mejora de la eficacia del aprendizaje y la formación en el lugar de trabajo, etc.." ${ }^{66}$

- Fomentar el reconocimiento de las cualificaciones y conocimientos obtenidos con el objeto fundamentalmente, de facilitar la movilidad y promover la educación permanente.

- Implantar los recursos materiales y personales necesarios para que el aprendizaje electrónico sea posible en las escuelas.

- Junto con los interlocutores sociales, los Estados miembros deberán desarrollar la capacidad de los servicios de empleo para adecuarlos a la demanda de mano de obra, así como fomentar la movilidad profesional y geográfica.

- Y por último, y en relación con la mejora de la capacidad de inserción profesional, los Estados miembros deberán combatir todas las formas de discriminación que impidan el acceso al mercado de trabajo, a la formación o educación. En especial, fomentará la inserción de colectivos como los inmigrantes, los minusválidos.

En cuanto al objetivo de desarrollar el espíritu de empresa y la creación de empleo, la actuación de los Estados miembros se concentrará en:

- El examen de los obstáculos existentes para la realización de una actividad por cuenta propia así como la creación de una pequeña empresa.

- La lucha, junto con los interlocutores sociales, contra el trabajo no declarado y su transformación en contratos regulares. 
- El fomento del desarrollo desde la esfera local, a tal fin "favorecerán las asociaciones con todos los actores interesados, incluidos los representantes de la sociedad civil' ${ }^{67}$.

- El desarrollo de sistemas impositivos más favorables para la creación de empleo "invirtiendo la tendencia a largo plazo dirigida a gravar el trabajo con mayores impuestos y cargas fiscales"

El tercer objetivo, en cuanto al fomento de la capacidad de adaptación de las empresas y de sus trabajadores, conlleva para los Estados miembros y los propios interlocutores sociales, una serie de compromisos que se concretan en.

- La celebración de acuerdos para la modernización de todos los aspectos relacionados con la organización del trabajo, "incluidas las fórmulas flexibles de trabajo, con el fin de lograr que las empresas sean productivas y competitivas, alcanzar el equilibrio necesario entre flexibilidad y seguridad, y aumentar la calidad de los puestos de trabajo "6:.

- En particular y teniendo en cuenta "la creciente diversidad de las formas de trabajo, examinaran la posibilidad de incorporar al Derecho nacional tipos de contratos más flexibles y garantizarán que los que trabajen con arreglo a los nuevos contratos flexibles se beneficien de una seguridad adecuada y de una categoría profesional más elevada. compatibles con las necesidades de las empresas y las aspiraciones de los trabajadores". ${ }^{70}$

Por último, y en cuanto al refuerzo de las políticas de igualdad de oportunidades entre hombres y mujeres, esta Decisión comunitaria que pretende seguir el camino iniciado en la Cumbre de Lisboa, señala una serie de aspectos en los que incidir, tales como:

- Medidas activas de política laboral que sean proporcionales a la tasa de desempleo femenino.

- El aseguramiento de la igualdad salarial por trabajo de igual valor.

- La realización por parte de los Estados miembros, de sistemas y procedimientos adecuados para la recogida de datos y la elaboración de un desglose por sexo de las estadísticas relativas al empleo.

- En definitiva, el desarrollo de todas las actuaciones encaminadas a la puesta en práctica de discriminaciones positiva a favor de las mujeres de manera que puedan compatibilizar su doble jornada de trabajo, con políticas de apoyo a la familia, disponibilidad de servicios asistenciales para los niños y otras personas

67. Decisión 2001/63/CE del Consejo. Ibídem Punto II.11.

68. Decisión 2001/63/CE del Consejo. Ibídem Punto II.11.

69. Decisión 2001/63/CE del Consejo. Ibídem Punto III.13.

70. Decisión 2001/63/CE del Consejo. Ibídem Punto III.14. 
a cargo de las mujeres principalmente, el reingreso al mercado de laboral después de períodos de ausencia por motivos familiares, etc...

Todos estos objetivos señalados en la Decisión del Consejo del año 2001, deberán tener su reflejo en los Planes nacionales de acción para el empleo, ya que aunque no se elaboran mediante instrumentos vinculantes para los Estados miembros sí responde al objetivo común en las esferas comunitarias y nacionales de crear y mejorar los niveles de empleo en los próximos meses.

\subsection{Los procesos de Cardiff y Colonia.}

Como ya se ha dicho, el Pacto Europeo para el Empleo estaba originalmente formado por la interacción de tres procesos, Luxemburgo, Cardiff y Colonia. Y aunque sólo el primero de ellos se dedica de forma monográfica y exclusiva a la política de empleo, los otros dos merecen también una cierta atención, siquiera para conocer sus contenidos y objetivos ${ }^{71}$.

El proceso de Cardiff fue establecido en la Cumbre celebrada en esta ciudad en junio de 1998, y tiene como objeto las reformas económicas destinadas a hacer del mercado único el motor de la creación de nuevos empleos, y para promover el espíritu empresarial y la competitividad. Su objetivo principal son las reformas estructurales para mejorar la competitividad y funcionamiento del mercado de bienes, de servicios y de capitales, al objeto de hacer posible el que las empresas europeas puedan aprovechar todo el potencial que el crecimiento de la economía europea ofrece ${ }^{72}$. El proceso se refiere a las medidas necesarias para desmantelar los obstáculos todavía existentes en el comercio entre los Estados miembros, incrementar la eficiencia del sector servicios, lograr un entorno para las pequeñas y medianas empresas más adecuado para lograr crecimiento y empleo, llegar a mercados de capitales eficientes y a una oferta adecuada de capital-riesgo, incrementar una política de competencia efectiva y reducir las ayudas estatales. En su desarrollo la Comisión ha tenido ocasión de pedir a la Unión y a los Estados miembros que introduzcan reformas económicas compatibles con la cohesión económica y social; que aseguren la participación de los accionistas; y ha solicitado de las autoridades públicas que garanticen un impacto efectivo de estas medidas en la competitividad y en el bienestar de los consumidores, así como que aseguren un entorno de regulaciones simple y de calidad.

El proceso de Cardiff, al igual que el de Luxemburgo, se articula mediante informes anuales sobre materias relacionadas con la producción y los mercados de capitales. Se le ha achacado la falta de participación de los interlocutores sociales y otras organizaciones representativas en su desarrollo y evaluación.

El proceso de Colonia, posterior en el tiempo a los de Luxemburgo y Cardiff, se impone sin embargo sobre ellos como una especie de superestructura. Según la

71. Para un estudio más detallado, NAVARRO NIETO, op.cit., pg.16.

72. NAVARRO NIETO, ibidem. 
definición que de este proceso dan las autoridades comunitarias, complementa a estos dos con un tratamiento integrador de ambos; de alguna manera, es el elemento que proporciona unidad y coherencia al conjunto de procesos, para que se pueda hablar de un único Pacto Europeo para el Empleo. Es este proceso el que en última instancia reúne todas las medidas de empleo de la Unión.

Su objeto principal es el de coordinar las políticas económicas. Intenta también mejorar la interacción entre los salarios y las políticas monetaria, presupuestaria y fiscal. El objetivo último de todas estas medidas es el de asegurar un crecimiento económico sostenido y no inflacionario.

El instrumento fundamental de este proceso es el diálogo macroeconómico, que se articula mediante dos encuentros al año, iniciados en 1999. En su desarrollo participan todas las instituciones políticas de la Unión, el Banco Central Europeo y los interlocutores sociales europeos. A partir del año 2000 se han venido elaborando unas Grandes Directrices de Política Económica que han servido de elemento central para todo el proceso de coordinación de ésta.

Se han encontrado paralelismos entre este proceso y las experiencias de concertación social desarrolladas en varios Estados miembros a lo largo de los años 80 del siglo pasado. En todos ellos se utilizaba el diálogo con los interlocutores sociales como principal instrumento de actuación; y también se incluían cuestiones relativas a políticas de rentas ${ }^{73}$. Sólo que en el Pacto Europeo para el Empleo la perspectiva es mucho más amplia, incluyéndose cuestiones de regulación del mercado y políticas económicas tradicionalmente excluidas de la concertación.

Posteriormente al diseño definitivo del Pacto Europeo para el Empleo en la Cumbre de Colonia de 1999, en la de Lisboa se diseñó un nuevo instrumento para el desarrollo de las políticas comunitarias, que ya empieza a ser conocido en la terminología europea como "proceso de Lisboa". En realidad, en las Conclusiones del Consejo Europeo de Lisboa se le denominó como "nuevo método abierto de coordinación, siendo calificado por el Consejo como "un nuevo método político".

A grandes rasgos, este método supone la determinación de directrices y calendarios específicos para lograr los objetivos; el establecimiento de indicadores cuantitativos y cualitativos, y de puntos de referencia; y la comparación de las prácticas idóneas. Las directrices europeas deben plasmarse en medidas de política nacional y regional mediante la fijación de objetivos específicos y la adopción de medidas que tengan en cuenta las diferencias nacionales y regionales. En su diseño participan los interlocutores sociales y la realidad social, y en su objeto se incluyen claramente medidas relacionadas con el empleo, por lo que sin duda la introducción de este nuevo método político afecta al desarrollo del Pacto Europeo para el Empleo.

73. NAVARRO NIETO, ibidem. 